\title{
The Formation and Dynamics of Teacher Roles in a Teacher-Student Groupwork during a Robotic Project (Fundamental)
}

\section{Pooneh Sabouri, New York University}

Pooneh Sabouri received her Ph.D. in Teaching and Learning, focusing on science education at New York University. She has a master's degree in mathematics education and statistics from The University of Texas at Austin and earned her bachelor's degree in Electrical Engineering from Sharif University of Technology in Iran. Pooneh is interested in teacher learning and how to co-develop theoretical tools with teachers to inform and expand their teaching practices. She is a postdoctoral associate at Tandon School of Engineering at New York University, where she studies teachers' experiences as they learn about robotics, how they envision incorporating robotics in their curriculum and challenges that they face.

\section{Dr. Shramana Ghosh, New York University Tandon School of Engineering}

Shramana Ghosh received her Ph.D. in Mechanical Engineering from University of California, Irvine in 2017, her Masters in Industrial Engineering from Texas A\&M University in 2013, and her Bachelors in Manufacturing Processes and Automation Engineering from University of Delhi in 2011. She is currently working as a postdoctoral associate at the Mechanical and Aerospace Engineering Department, NYU Tandon School of Engineering, NY, USA. In this role she supports and studies use of robotics in K-12 STEM education. Her other research interests include robotics, mechanical design, and biomechanics.

\section{Mr. Abhidipta Mallik, New York University Tandon School of Engineering}

Abhidipta Mallik received his B.Tech. degree in Electronics and Communication Engineering from the West Bengal University of Technology, Kolkata, India, and M.Tech. degree in Mechatronics from the Indian Institute of Engineering Science and Technology, Shibpur, West Bengal, India. He has one year and ten months of research experience at the CSIR-CMERI, India. He is currently a Ph.D. student in Mechanical Engineering at NYU Tandon School of Engineering, Brooklyn, NY, where he is serving as a research assistant under an NSF-funded ITEST project.

\section{Dr. Vikram Kapila, NYU's Tandon School of Engineering}

Vikram Kapila is a Professor of Mechanical Engineering at NYU Tandon School of Engineering (NYU Tandon), where he directs a Mechatronics, Controls, and Robotics Laboratory, a Research Experience for Teachers Site in Mechatronics and Entrepreneurship, a DR K-12 research project, and an ITEST research project, all funded by NSF. He has held visiting positions with the Air Force Research Laboratories in Dayton, OH. His research interests include K-12 STEM education, mechatronics, robotics, and control system technology. Under a Research Experience for Teachers Site, a DR K-12 project, and GK-12 Fellows programs, funded by NSF, and the Central Brooklyn STEM Initiative (CBSI), funded by six philanthropic foundations, he has conducted significant K-12 education, training, mentoring, and outreach activities to integrate engineering concepts in science classrooms and labs of dozens of New York City public schools. He received NYU Tandon's 2002, 2008, 2011, and 2014 Jacobs Excellence in Education Award, 2002 Jacobs Innovation Grant, 2003 Distinguished Teacher Award, and 2012 Inaugural Distinguished Award for Excellence in the category Inspiration through Leadership. Moreover, he is a recipient of 2014-2015 University Distinguished Teaching Award at NYU. His scholarly activities have included 3 edited books, 9 chapters in edited books, 1 book review, 63 journal articles, and 164 conference papers. He has mentored 1 B.S., 40 M.S., and 5 Ph.D. thesis students; 64 undergraduate research students and 11 undergraduate senior design project teams; over $500 \mathrm{~K}-12$ teachers and 130 high school student researchers; and 18 undergraduate GK-12 Fellows and 59 graduate GK-12 Fellows. Moreover, he directs K-12 education, training, mentoring, and outreach programs that enrich the STEM education of over 1,000 students annually. 


\section{The Formation and Dynamics of Teacher Roles in a Teacher-Student Groupwork during a Robotics Project (Fundamental)}

\section{Introduction}

Over the last decade, with the ever-increasing demand of STEM majors for the job market and the introduction of Next Generation Science Standards (NGSS) [1], the need for introducing and integrating engineering design and practices within the K-12 curriculum has risen. Accordingly, professional development programs have been seeking to prepare teachers for incorporating engineering design concepts and various engineering practices into their curriculum. As an example, over the last two decades, educational robotics has become increasingly popular as (i) a learning tool that is deemed to promote students learning of STEM topics and (ii) a learning object that can mediate student learning about computational skills and engineering practices [2-4].

Given the novelty of educational robotics, and the accumulating evidence showing its impact on improving student learning [5-7], it is important to prepare both in-service and pre-service teachers to incorporate robotics in their curriculum. Thus, educational programs for teacher preparation and professional development have been aiming at engaging teachers in robotics-infused pedagogical practices [8-10]. Prior researchers have studied various robotics programs to examine their effectiveness, for example, with a focus on evaluating: teacher knowledge [11], self-efficacy [12], and student learning outcomes [13,14]. However, even after participating in robotics-based professional development programs, often teachers seeking to implement their learning in the classroom are still relative novices in robotics technology. Thus, it is important to consider and examine the question that "how do teachers resolve the tension between learning robotics alongside their students and teaching them?" In particular, how being a novice changes teacher performance and roles that they would take on in facilitating student learning? In this paper, we aim to address this question by studying the interactions between two teachers and four students as they learned about robotics and worked together as a group to accomplish solving an engineering problem. We asked (i) what actions and strategies did the teachers utilize within the group (teacher roles)? and (ii) how did these actions impede or facilitate student learning about robotics and engineering practices?

\section{The Notion of Roles in Various Teaching and Learning Environments}

Our study was inspired by the research literature on informal learning [15-17]. In their review, Rogoff and her colleagues identified informal learning with several characteristics including: "being interactive and embedded in meaningful activity"; "assessment occurs in support of contributing to the activity, not for external purposes"; and "involves building on individual's initiative, interest, and choice" [16]. Prior researchers have emphasized that informal learning is 
not simply about or being limited to the location of learning activity (e.g., out of the school), instead it is concerned with: the way that learning is organized, being fluent around the goals, the roles that participants take, and the quantum of their contribution. For example, museums are often considered as places where informal learning occurs [18-20]. In a study on the role of parents on developing children's scientific thinking, Crowly and colleagues [21] studied the interactions between parents and children as they visited a children's museum. Researchers noted that the parents encouraged children to explain their observations when engaging with some of the exhibits and asked them to propose alternative ideas or solutions for the tasks. Moreover, the parents explained the activities or provided interpretations for the children's observations. The study of [21] depicted how within the setting of a museum, which does not provide any direct guidelines for visitors, the parents assumed the role of explainer and mediated the children's learning. The researchers also argued that in several instances parent actions limited the children's explorations and constrained their learning opportunities.

In another study [22], Chavajay and colleagues focused on interactions in an after-school program between children and their undergraduate mentors. The after-school program in their study involved various games and educational activities (e.g., computer programming) for young children from low-income/minority background. The undergraduate students in the university were encouraged to volunteer in the program as mentors. The purpose of the after-school program was creating opportunities for informal learning and collaboration, both for children and undergraduate students. The researchers followed a group of undergraduate students to examine their experience in this program and how they understood their teacher/learner roles within this informal setting. Many of the undergraduate students struggled with the unstructured format of the after-school program wherein the children did not necessarily acknowledge them as "teachers" whose instructions or ideas needed to be followed. Instead, in many instances, the children took the role of authority to suggest their own ideas and to enact their own plans. The researchers showed that interactions with children allowed several undergraduate mentors to reflect on their assumptions. They re-conceptualized learning as a collaborative action as opposed to the transmission of knowledge from a teacher to students [23] and overcame their frustrations and struggles with the program. Accordingly, they began to play the role of a collaborator and partner with children and developed productive and meaningful learning experiences for themselves and the children.

In our work, for several years, we have been implementing workshops for teachers and their students, to allow them to jointly learn the fundamental concepts, engineering design, and engineering practices through hands-on learning with robotics. Using the characteristics of informal learning [16], we identify our workshops as a semi-formal learning environment. In the beginning of the workshop, teachers and students were positioned as learners who received short lectures and presentations about robot components, robot building, and robot programming. Moreover, teachers and students worked in teams to engage in hands-on structured learning, which 
augmented the robotics fundamentals from corresponding lectures, reinforcing and imparting a greater sense of understanding. Next, the teacher-student teams were directed to solve a given challenge by designing, building, and programming an integrated robotics solution. Within each team, teachers and students had the freedom to organize their teamwork with no guidelines from the research team. Thus, within each team, an informal learning experience emerged where teachers and students had to negotiate the tasks and their roles to solve the given robotics challenge. In that unfolding dynamics, we were interested to learn, within the team, what roles the teachers would assume and whether their roles would change and evolve as a result of the team dynamics. Next, we will discuss the theoretical ideas that we used to address our questions and analyze the data.

\section{Theoretical Framework}

In understanding and characterizing the roles in teacher-student interactions within the robotics workshop, we used the 3R framework introduced by [24]. This framework characterizes a social practice with routines, roles, and responsibilities. The routines describe what actions occur in practice and what the accepted patterns of such actions are. For example, a known routine within science classrooms is the initiation of a question by a teacher, followed by a student's response, which is evaluated by the teacher - that is, the initiate-response-evaluate (IRE) routine [25]. Roles direct the attention to who within the practice is responsible for taking specific actions (e.g., the teacher takes the role of questionnaire and evaluator while the students are the responders). Finally, the responsibility highlights what successfully playing a specific role within that practice entails. Using the example of teacher and student in a science classroom, the responsibility of the teacher's role is asking questions that are relevant to the subject and at the level of the students' knowledge.

For engineering practice in general, and working with robotics in particular, the routines can be considered equivalent to engineering practice defined by [26] as an "iterative process that begins with the identification of a problem and ends with a solution that takes into account the identified constraints and meets specifications for desired performance." Alternatively, the steps of engineering design process (EDP) can serve the purpose of routines of engineering practice. Authors in [27] define EDP as a cyclic process consisting of five steps: asking a question and exploring what has been done by others, imagining possible solutions, planning to enact the solution, creating the required artifacts, and improving the solution based on results. Using a more fine-grained decomposition of tasks and highlighting the importance of communication of results, [28] details an eight step EDP as: (1) identifying and (2) researching a problem, (3) developing and (4) selecting solutions, (5) prototyping, (6) testing and evaluation, (7) communicating solutions, and (8) redesigning. Note that the aforementioned IRE routine had an inherent decomposition of roles ascribed to the teacher and student. In contrast, the five or eight steps of the EDP routine often take place within a group without predefined roles for individuals and each member may perform more than one of these steps individually or collaboratively. That is, usually 
the roles are fluent between members, and accordingly, the responsibilities (i.e., what it means to take any of the roles) are defined through group negotiation.

We anticipate that when teachers and students work together, due to the pre-existing hierarchy of authority between them, additional roles and responsibilities might emerge. Several studies have examined the interactions between young children, often elementary and kindergarten, and their teachers when working with educational robotics $[29,30]$. The researchers recognized a routine where students identified problems, followed by teachers' guidance for helping them develop a solution, and ending with the students proposing solutions-which parallel some of the aforementioned steps of the EDP. Puvirajah and colleagues [31] examined the interaction between high school students and their mentors in a robotics club preparing for robotics competition. They focused on characterizing member's language and the mediation of power among the members. The authors of [31] argued that due to the voluntary nature of the robotics club a collaborative community was formed among the members and the power relationship was fluent regardless of the expertise of the team members.

In our workshop (see subsection 4.1) teachers and students were engaged in enacting the steps of EDP. However, similar to [31], the unstructured format of the teams allowed the teachers and students to take different roles and they had to negotiate their responsibilities as they progressed through the projects. Then, focusing on the teachers, we examined what roles they performed and how they conceptualized their responsibilities within those roles. We were interested in identifying the additional roles, besides the ones related to the steps of the EDP routine, that emerged through teacher-student interactions in the workshop.

\section{Methods}

This study is part of a larger project that has engaged three cohorts of high school teachers and students over three years to learn about robotics and entrepreneurship. This paper is a case study focusing on one group of teachers with their students who participated in the third year of the project. The case study method was selected as it provides the tools for "capturing the different elements that contribute to peculiarities of the phenomenon under the investigation [which] enables the researchers to expose what may have contributed to the phenomenon" [32].

4.1. Context The context of this case study is a four-week summer robotics program for high school teachers and students. One of the requirements for teacher attendance was that teacher applicants recruit two students from their schools and participate in the program as a team. This novel structure of the participants (teachers with students) was decided in response to the feedback that the research team received from teachers who attended in previous professional development programs on using robotics for STEM education. Teachers stated that working alongside the students would help them in determining how to adapt the tasks for the classroom and adjust the 
implementation of the lessons or skills. Additionally, the research team anticipated that positioning teachers and students within a team would reveal various actions that teachers might take as they work with their students.

During the first two weeks of the workshop, engineering graduate students under the supervision of an engineering faculty introduced relevant robotics concepts, robot components, and robot programming to the participants. In addition to learning about how to design, build, and program a robot, participants were introduced to some ideas of entrepreneurship and how to present their engineering products to businesses. The ultimate goal of the workshop was that teachers and students learn about engineering practice and how its product can be turned into business models. Informed by a project-based learning framework, a challenge was introduced to the teams. During the next two weeks of the workshop, the teams had time to design and iteratively modify their robots and program it to address the given challenge. The challenge was inspired by a real-world scenario of garbage collection and recycling by the New York City (NYC) Department of Sanitation. The teams were asked to design and program their robots to collect trash, sort it, and deliver it to the relevant recycling facilities. A map with several streets and houses was presented where trash bins with various types of trash were randomly put in front of houses. The designed robots needed to be able to (i) identify the presence of the trash bin; (ii) determine the type of trash; and (iii) take the trash to the relevant facilities. Each part of the challenge had multiple solutions that the teams needed to decide on and accordingly design and program their robots. Additionally, the teams were asked to prepare a presentation, use the entrepreneurship ideas, and pitch their work to potential business sponsors. Embedded in a real-life scenario and being an open-ended problem, the assigned project followed the characteristics of informal learning introduced by [16].

4.2. Participants A total of 10 teachers and 22 students from 8 inner-city schools attended the workshop. In this paper, we focus on one group of two teachers and four students. These two teachers, referred with pseudonyms Michael and Leo, came from two different schools and recruited two students each from their schools. The two teachers did not know each other prior to the program and were randomly assigned to work as a team together.

Michael had started his teaching career as a mathematics teacher. Through Math for America he took a course in Arduinos that sparked his interest in robotics and later he started to teach and coach robotics clubs in his school. In his current school, the school administration was seeking to develop and implement a new curriculum for robotics and Michael had been assigned to develop the curriculum. For him, attending this robotics workshop was an opportunity to learn more about robotics and to get advice about the curriculum that he was planning on developing.

The two students who attended with Michael were members of the robotics club in their school and had knowledge of programming and robotics. However, they were not familiar with the Arduino programming environment introduced in the current workshop. In our first interview with 
Michael, he explained that at his school multiple students wanted to attend the workshop, and he selected the two students who, in his opinion, were "genuinely interested" and had "good work habits" which he described as:

You need certain baseline of perseverance to work through problems, willingness to look things up when the answers are not right in front of you. I think if you don't have [these habits], what ends up happening is that you end up in [a] frustration level, where instead of sort of growing through the frustrations, you push back. (Michael, interview 1)

He added that the other students that he did not recruit for this workshop had not developed these work habits yet and he was worried that, had those students attended, they would have not benefited from the challenges given in this workshop.

Leo is the software coordinator at his high school and was recently assigned to be the advisor of the robotics club. He has a background in computer science and taught 12 years in junior high school. Leo did not personally want to participate in the workshop but the students asked him to accompany them so they could attend the workshop.

I do not want to use this word, but I was forced to do it, not by administration, it was a student force driven that got me here [...]. I think, the teachers are doing it for the students. They said they had to have a teacher so I volunteered others [teachers], [...] but I guess they had their plans and so I am here but I am having a good time [in the workshop]. (Leo, interview 1)

Leo mentioned that multiple students wanted to attend the program but he did not elaborate if he had any saying in choosing them or what the selection criteria were. Compared to Michael, Leo was less interested in participating in the learning activity and setting up the robots and often was the observer within the team.

\section{Data Collection and Analysis}

For data collection, a camera was set up at the table where Michael, Leo, and the four students were working and it recorded their interactions throughout the program. A member of the research team sat at their table and took field notes of the teamwork. Two other members of the research team conducted group interviews with Michael and Leo at the end of the second, third, and last weeks of the projects. The data for this paper was collected from the field notes and transcripts of the interviews. The videos were used for verifying excerpts of the field notes that were coded.

5.1. Phase I of the analysis Adapted from [30,33], the following coding scheme was developed for differentiating teacher roles. 
- Assistant: The teacher assisted the students in fixing a technical problem or proposing a solution for a challenge that students were facing.

- Emotional Support: The teacher talked (e.g., encouraging them with praising words or talk privately) with students who appeared to be tired or uninterested in the task at hand.

- Learner: The teacher joined the students and played the role of an authentic learner who wanted to learn about building, coding, or solving problems.

- Task Manager: The teacher distributed the tasks among students and/or reminded them about timing.

- Reviewer: The teacher asked students to verbalize their solutions, suggestions, or their prior knowledge about the robot to the other team members and ensured that knowledge was shared among the students.

- Facilitator: The teacher explained relevant science, robotics, or programming concepts to the students. This role was different from assistant, as in the facilitator role, the teacher would explain concepts that students did not necessarily need to learn to solve the problems for their robotic challenge. However, the teacher felt that such concepts were beneficial for their learning experience in general. While in the assistant role, the teacher would answer questions or propose ideas about the immediate problems that students had for the given challenge in the workshop.

- Information Collector: The teacher inquired about information from other teams in the workshop either about possible ways to address the technical issues or about the logistics of the program (e.g., the requirements for the final presentation).

A thematic analysis approach $[34,35]$ was used to code the field notes where we marked what the observer wrote about teacher acts based on one of the above codes. The purpose of this phase of analysis was to investigate whether there was a pattern to the roles that teachers took throughout the workshop. The observer neither documented how long these acts took place nor stated any interpretation about the quality of the act (e.g., how extensive or elaborate the teacher assistance was in any specific moment). Thus, the current coding only indicated that, from the observer's perspective, these roles took place throughout the workshop.

5.2. Result of the phase I Figure 1 shows the results of coding, the frequency of each code, and how the frequency changed over time during the workshop. The results indicate that initially, during the first week of the workshop, the teachers often took the role of facilitator that is explaining the concepts and/or coding ideas broadly relevant to the robotics task at hand. The first two weeks of the workshop were spent on learning the fundamental concepts of robotics (including physics, mechanics, circuits, and electronics) and Arduino programming. It appears that during this period, the teachers took their presumed role of "being a teacher" and facilitated student's 
learning. Moreover, the teachers played the role of assistant where they would help students set up the robot itself including attaching different parts and wiring it.

As the workshop progressed and the teams began to program their robot for collecting and sorting trash bins, the teachers became learner themselves and joined the students in solving problems, troubleshooting, and coding. Being a task manager was another role that the teachers initially took, during the first two weeks, but then they abandoned this role until the end of the workshop. Towards the end of the workshop, teams needed to organize their presentations and finalize their coding, and thus, teachers considered their responsibilities to manage the work and ensure that the team accomplished the required tasks.

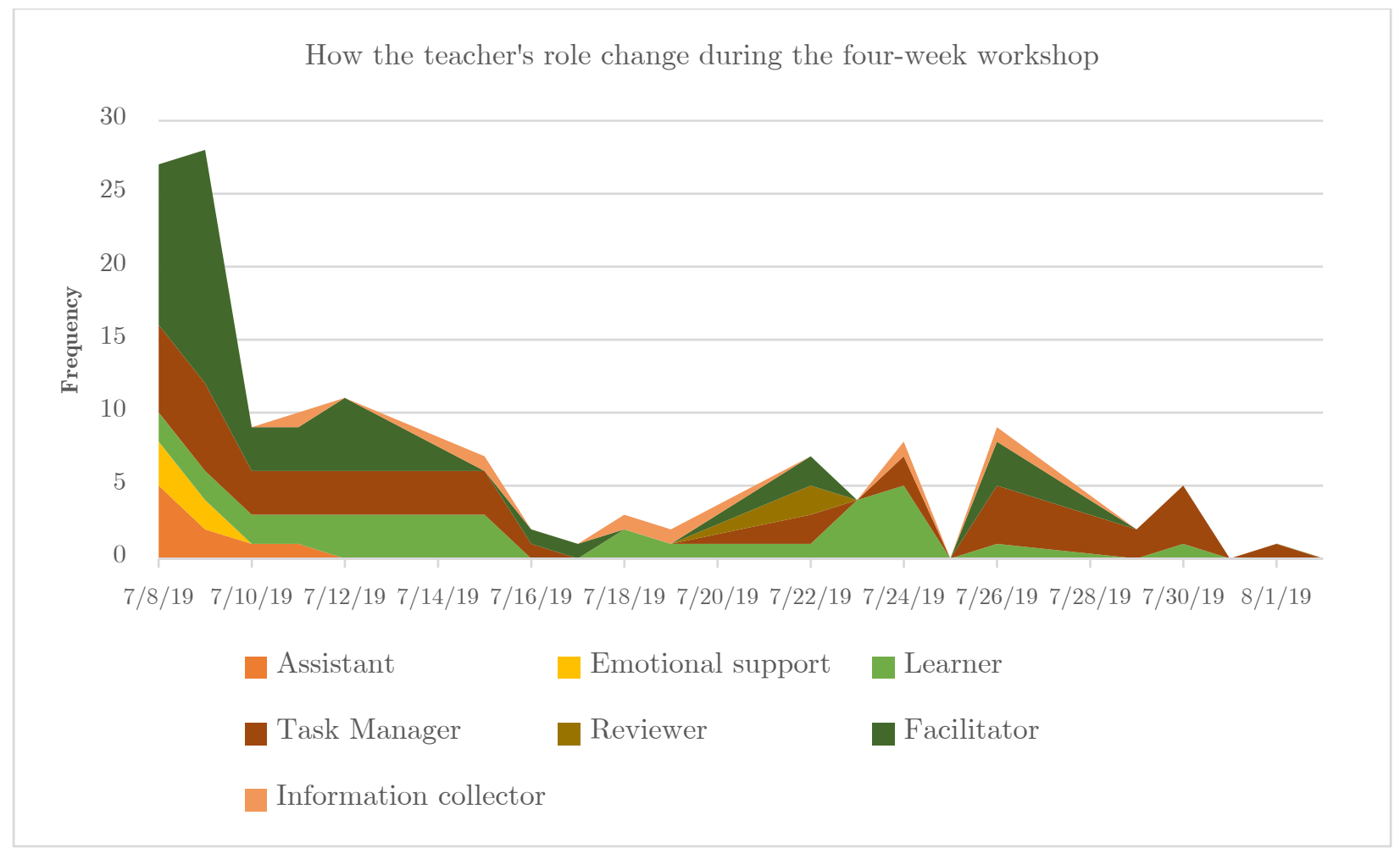

Figure 1. The roles that teachers Michael and Leo took during the workshop

In phase II of the analysis, we examined the transcripts of the interviews with Michael and Leo to understand how they saw their roles in this workshop and why they decided to take on those roles. Next, we present excerpts from the interviews which indicate that as the teamwork progressed, teachers further appreciated the authenticity of the robotic challenge and its impact on developing students' genuine interests in engaging in problem-solving and overcoming difficulties. Moreover, they acknowledged the need for similar projects within the school settings where students are not only learning scientific and engineering concepts but they also acquire social skills to be professional. 
5.3. Teachers' perceptions of their roles and responsibilities At the beginning of the workshop, in the first two weeks when the teams were introduced to the fundamental concepts, the research team presented a lecture on the topic of entrepreneurship. In the first interview, both Michael and Leo pointed out that students were not particularly interested in the topic, and they, as teachers, had to further explained to them why the topic was relevant to them if they intend to pursue an engineering career.

One of [my students], has to take that class, the entrepreneurship class in September [...]. I had to explain to them how that class [and the presentation of entrepreneurship in this workshop] falls into, you know, building not only about robot but something, you know, so they can, put it in the market and then so on and so forth. (Leo, interview 1)

Leo considered his responsibility to explain the connection between engineering and entrepreneurship for the students knowing the importance of it in engineering practices. In coding, we labeled his role as a facilitator, but Leo's explanation indicates that, in his view, the responsibility of this role was beyond explaining the scientific or technical concepts. Enacting the role of facilitator, for him as the teacher of his students, entails highlighting the non-technical aspects of the engineering career for the students as well.

Being the teachers in the team did not keep Leo and Michael from being learners themselves. However, in their learner role, they purposefully tried not to dominate the leadership of their team and allowed the students to own their learning as illustrated below.

Once [the students] take over, you need to really step aside, let them do the thinking and asking the questions so that they can own whether they are learning, because we know what to do already [to learn a new topic], so we know that we have to be on task, that we have to pay attention but, you know, they are still in high school, so once they take over, and it is very nice to see the four students come together, one or two working on the code, and two working on the project or the artifact. It is rewarding. (Leo, interview 1)

Leo's response indicates that the moments that he (or Michael) were sitting aside or appeared to be idle members, they were providing space for students to develop learning skills on their own without teachers constantly guiding them what to do. Michael elaborated that, even in those moments of stepping aside, he was overseeing the student actions and indirectly mediated student learning. We labeled these teacher actions as a reviewer, but Michael's explanation indicated that his goal in taking this role was not merely ensuring that the project would be successful but to make students conscious of their actions. In particular, he wanted students to know what the consequences would be if they neglected the directions given by the presenters or ignored the details. 
One of the things that I find myself doing a lot is, if I see a student doing something that might not necessarily be investigating in the interest of the team, it is not so much [telling the student] 'you are doing that wrong', like, [instead] I would say something,' hey I just want you to do me a favor and look at [...], [the student would say] 'oh I wasn't supposed to do that', and the answer [to the student] is 'no, it is not really we are not supposed to', you know, you have a goal to execute, you see what others are doing to execute and then the choice is yours, [...]. But you [the student] have to get to the point that you are able to own that choice and say 'I get that I've put that level of work', whatever that level is, 'for the goal of this much and I am self-aware of that'. (Michael, interview 1)

One of the other roles that Leo and Michael took only during the first days of the workshop was an emotional supporter where the focus was on learning the concepts and coding in a school-like structure. However, starting with week three, when teams began working on the collecting and sorting trash bin challenge, the teachers did not play the emotional supporter role as often as in the beginning. Michael explained how the authenticity of the robotic challenge allowed the students to take the ownership of the task and become engaged in the work where there was no need for outside encouragement.

[In this workshop] suddenly there is no longer in this mode of 'teacher show me how do something' now it is a project. I have an end goal that I want to take ownership for and that end goal is not I want a 90 [grade], I want an 80 [grade], I want a pass [grade]. [Instead] I want to make this thing work and the grade no longer matters, [...] I want that robot to navigate that maze, and it is not about that grade my teacher is giving me, I want to get it there, so you have this inherent drive coming from inside, to accomplish that goal. That is different from the traditional school. (Michael, interview 2)

Michael's explanation of student engagement in the task aligned with findings of other studies [31], where a sense of agency and ownership of the task developed student interest and there was less or no need for verbal praise or teacher encouragement to engage the students in the task. However, Michael pointed that, even though the students might be motivated in doing the tasks, they might not necessarily know how to address the challenges. Thus, it is the responsibility of the teacher in the team to model what being a learner can look like.

In other times I've been like, alright, I am the learner in the room too, it is important for me to model, you know, what this learning process is like. (Michael, interview 2)

He added that, in addition to modeling being a learner, there were moments that the team needed some task management and hence, he or Leo became the task manager. There were also moments that students organically adopted the task manager role themselves. 
It feels like for the most part it is gone pretty smoothly in terms of us organically figuring out what it means to get done, who would do what, when it is time to sort of, bringing everyone together and go alright guys, here is what we need to do, and sometimes that is one of us saying it, as a teacher, and other times it is one of the students saying it. (Michael, interview 2)

Both Leo and Michael explained that, given the complexity of the robotic challenge, students were frustrated with technical issues and it was part of the teacher responsibility to direct their learning and suggest possible ways to address the problems. Michael described those moments as a "positive frustration" that results in student learning and development.

We have been on this project for more than a week and it is kind of challenging to keep running into the same problem over and over again, you can see their faces drop a little bit, when one thing they think they've solved it, it doesn't work. Or when they are like, what else I can do? You get that kind of blank stare. But we see a lot of times where they're perked up and, like, excited, oh! Let's try this, let's try that. So [what] I am assessing is some productive frustration. (Michael, interview 2)

Michael's interpretation of the "productive frustration" showed that, even though he still considered himself as the teacher in his interaction with the students in the team, his role had shifted from knowledge holder to a facilitator who might know the answer, but will suggest possible actions to find the answer and support students' problem-solving task.

In the last interview, Michael and Leo pointed out that the most rewarding aspect of attending the workshop for students was becoming college-ready. They elaborated that the unstructured format of the setting, the open-ended project, and the authenticity of the proposed challenge (a real-life scenario) gave the students an understanding of how to be professionals and be able to navigate and oversee their learning. Leo stated that the experience in the workshop gave the students an understanding of the work even beyond college life.

It is the fact that we are taken out of a classroom setting, that is so traditional and it hasn't changed in many many years, so it helps with that gap between high school and college. So now [the students] know what the real world is like and they know that they will not be ready (without the necessary skills), when they go to college, [...] a lot of students have come to us and complain about it: 'why we are not as open as we are in college?', 'we are not ready', [...] we [school administration] still have this setting of 34 [to] 35 students and we still have this attendance thing, and this 40 minutes only, and this 'you don't come late', and 'you don't have [your] homework [with you]', [...] 'sit', 'be quiet', 'don't talk', [...]. We have so many don't in high school. [...] the discrepancy [...] that we have between college and work, so when we get out of college, there is this huge gap of what, [...] I didn't 
study to do this. And it happened to me, I think it happens to all of us. So this [experience in the workshop] is the taste of what they are expected [to do] not only in college, but also in a company. (Leo, interview 3)

In our view, Leo's response indicates that one aspect of the responsibility within all the roles that he and Michael took in this teamwork was recognizing opportunities for student growth. In his view, student growth was not limited to learning engineering practices but becoming adults who are getting ready to enter professional life. Thus, it was their roles allowing students to explore, discover and in moments struggle to develop the necessary skills.

\section{Conclusion}

In this paper we studied the roles that two teachers, Leo and Michael, played in the group activity with their students during a robotic workshop. The tasks defined for teachers and students in our workshop followed the steps of EDP routine [27,28]. Thus, we anticipated that teachers and students would play roles corresponding to the steps of EDP. However, we were interested to know what additional roles would emerge as the results of teachers and students working together. Moreover, what teachers perceived as their responsibilities associated with those emergent roles.

We grounded our study in the literature on the informal learning environment, given the structure of the workshop in our research project. However, research on how teachers understand, negotiate, and implement their roles with students is not limited to informal settings. Current reform ideas from education research provide evidence on the effectiveness of student-centered learning, where students are given more autonomy and responsibility for their own learning [36,37]. However, prior research studies show that teachers often face various challenges in understanding their roles and transforming their pedagogical practices in setting these learning environments [38]. In particular, research has shown that in a student-centered learning environment, teachers are concerned with covering the curriculum [39], students' results on achievement tests [40], and classroom management [41]. Our study aims to contribute to this body of knowledge by investigating similar questions about teachers' roles in an informal setting where students' performance on formal assessments does not constrain teachers in determining their roles and actions with students.

Similar to the study by Chavajay and colleagues [22], Leo and Michael played various roles in ways that they thought would assist the team and students in accomplishing the given challenge. Unlike other teachers in the workshop, Michael and Leo were not frustrated with the informal structure of the workshop and quickly adapted to the dynamic nature of their roles in the team. Initially, when the workshop was focused on teaching the concepts of robot design, robot building, and robot programming to the teams, Michael and Leo stepped into their "teaching role" and ensured that students in their team were understanding the presented ideas. As the team began to 
work on the given project, teachers gradually left their authoritative roles and became collaborators in the team. However, interviews with Michael and Leo revealed that, in addition to supporting students in being successful in the workshop, they also recognized participation in the workshop as an opportunity for students to become professionals. Hence, there was always a pedagogical aspect interwoven into their responsibilities for each role that they took.

Other teachers in this workshop did not necessarily share similar experiences as Michael and Leo did. In our conversation with another team, the two teachers who had limited knowledge of robotics had a very difficult time reconceptualizing their authoritative role with the students. Even though they did not have the expert knowledge to facilitate student learning, they were uncomfortable taking the learner position and engage in problem-solving along with their students. Further research studies are needed to understand what factors might prevent teachers from reconceptualizing their roles and giving agency and authority to their students in a similar learning environment.

\section{Acknowledgments}

This work is supported in part by the National Science Foundation grants ITEST DRL: 1614085, DRK-12 DRL: 1417769, and RET Site EEC: 1542286; and NY Space Grant Consortium grant 76156-10488. The authors thank the high school teachers and their students for their participation in this study.

\section{Reference}

1. NGSS Lead States, (2013) Next Generation Science Standards, Washington, DC: National Academies Press.

2. Alimisis, D., et al., (2010) "Introducing robotics to teachers and schools: Experiences from the TERECoP project," Proceedings for Constructionism, 1: p. 1-10.

3. Sullivan, A. and M.U. Bers, (2016) "Robotics in the early childhood classroom: Learning outcomes from an 8-week robotics curriculum in pre-kindergarten through second grade," International Journal of Technology and Design Education, 26(1): p. 3-20.

4. Leonard, J., et al., (2016) "Using robotics and game design to enhance children's self-efficacy, STEM attitudes, and computational thinking skills," Journal of Science Education and Technology, 25(6): p. 860-876.

5. Eguchi, A. (2014) "Robotics as a learning tool for educational transformation," Proc. 4th International Workshop on Teaching Robotics, Teaching with Robotics \& 5th International Conference on Robotics in Education, Padova, Italy, p. 27-34. 
6. Amy, E. (2014) "Educational robotics theories and practice: Tips for how to do it right," in Robotics: Concepts, Methodologies, Tools, and Applications, IGI Global: Hershey, PA, p. 193223.

7. Mehul, B. (2014) "Reasoning about space, actions, and change: A paradigm for applications of spatial reasoning," in Robotics: Concepts, Methodologies, Tools, and Applications, IGI Global: Hershey, PA, p. 315-349.

8. Ortiz, A.M., et al., (2015) "The power of educational robotics as an integrated STEM learning experience in teacher preparation programs," Journal of College Science Teaching, 44(5): p. 4247.

9. Bers, M.U. and M. Portsmore, (2005) "Teaching partnerships: Early childhood and engineering students teaching math and science through robotics," Journal of Science Education and Technology, 14(1): p. 59-73.

10. Chambers, J.M. and M. Carbonaro, (2003) "Designing, developing, and implementing a course on LEGO robotics for technology teacher education," Journal of Technology and Teacher Education, 11(2): p. 209-241.

11. Kim, C., et al., (2015) "Robotics to promote elementary education pre-service teachers' STEM engagement, learning, and teaching," Computers and Education, 91: p. 14-31.

12. Jaipal-Jamani, K. and C. Angeli, (2017) "Effect of robotics on elementary preservice teachers' selfefficacy, science learning, and computational thinking," Journal of Science Education and Technology, 26(2): p. 175-192.

13. Scaradozzi, D., et al., (2019) 'Implementation and assessment methodologies of teachers' training courses for STEM activities,” Technology, Knowledge, and Learning, 24(2): p. 247-268.

14. Nugent, G., et al., (2016) "Robotics camps, clubs, and competitions: Results from a US robotics project," Robotics and Autonomous Systems, 75: p. 686-691.

15. Rogoff, B., (2014) "Learning by observing and pitching in to family and community endeavors: An orientation," Human Development, 57(2-3): p. 69-81.

16. Rogoff, B., et al., (2016) "The organization of informal learning," Review of Research in Education, 40(1): p. 356-401.

17. Paris, S.G., (1997) "Situated motivation and informal learning," Journal of Museum Education, 22(2-3): p. 22-27.

18. Holmes, J.A., (2011) "Informal learning: Student achievement and motivation in science through museum-based learning," Learning Environments Research, 14(3): p. 263-277.

19. Lin, A.C.H., et al., (2012) "Understanding web enjoyment experiences and informal learning: A study in a museum context," Decision Support Systems, 53(4): p. 846-858.

20. Hein, G., (2009) "Learning science in informal environments: People, places, and pursuits," Museums and Social Issues, 4(1): p. 113-124.

21. Crowley, K., et al., (2001) "Shared scientific thinking in everyday parent-child activity," Science Education, 85(6): p. 712-732.

22. Chavajay, P., et al. (2005) "Teachers, mentor, friends?: Undergraduates' engagements with Latino children in an after-school program," in Teaching and Community: Contributions of Situated and Participatory Approaches to Educational Innovation, L. Pease-Alvarez and S.R. Schecter (Editors), Routledge, p. 150-169. 
23. Gutiérrez, K.D. and B. Rogoff, (2003) "Cultural ways of learning: Individual traits or repertoires of practice," Educational Researcher, 32(5): p. 19-25.

24. Ford, M.J. and B.M. Wargo, (2007) "Routines, roles, and responsibilities for aligning scientific and classroom practices," Science Education, 91(1): p. 133-157.

25. Lemke, J.L., (1990) Talking Science: Language, Learning, and Values, Norwood, NJ: Ablex Publishing Corporation.

26. National Research Council, (2010) Standards for K-12 Engineering Education? National Academies Press.

27. Museum of Science. Engineering is Elementary. Available from: http://www.eie.org/eiecurriculum.

28. Massachusetts Department of Education, (2006) Massachusetts Science and Technology/Engineering Curriculum Framework, Malden, MA: Massachusetts Department of Education.

29. Kucuk, S. and B. Sisman, (2017) "Behavioral patterns of elementary students and teachers in oneto-one robotics instruction," Computers and Education, 111: p. 31-43.

30. Liu, E.Z.-F., et al., (2013) "An analysis of teacher-student interaction patterns in a robotics course for kindergarten children: A pilot study," Turkish Online Journal of Educational Technology, 12(1): p. 9-18.

31. Puvirajah, A., et al., (2012) "Examining the mediation of power in a collaborative community: Engaging in informal science as authentic practice," Cultural Studies of Science Education, 7(2): p. 375-408.

32. Timmons, V. and E. Cairns (2010) Case Study Research in Education, in Encyclopedia of Case Study Research, A.J. Mills, G. Durepos, and E. Wiebe (Editors), Sage Publications: Thousand Oaks, CA, p. 100-102

33. Webb, N.M., (2009) "The teacher's role in promoting collaborative dialogue in the classroom," British Journal of Educational Psychology, 79(1): p. 1-28.

34. Clarke, V. and V. Braun, (2013) "Teaching thematic analysis: Overcoming challenges and developing strategies for effective learning," The Psychologist, 26(2): p. 120-123.

35. Braun, V. and V. Clarke (2012) Thematic analysis, in APA handbook of research methods in psychology, Vol 2: Research designs: Quantitative, qualitative, neuropsychological, and biological, American Psychological Association: Washington, DC, US, p. 57-71.

36. Odom, A.L. and C.V. Bell, (2015) "Associations of middle school student science achievement and attitudes about science with student-reported frequency of teacher lecture demonstrations and student-centered learning," International Journal of Environmental and Science Education, 10(1): p. 87-97.

37. Yukhymenko, M.A., et al., (2014) "Thematic analysis of teacher instructional ractices and student responses in middle school classrooms with problem-based learning environment," Global Education Review, 1(3): p. 93-110.

38. Keiler, L.S., (2018) “Teachers' roles and identities in student-centered classrooms," International Journal of STEM Education, 5(1): p. 34.

39. Boddy, N., et al., (2003) "A trial of the five Es: A referent model for constructivist teaching and learning," Research in Science Education, 33(1): p. 27-42. 
40. Keys, C.W. and L.A. Bryan, (2001) "Co-constructing inquiry-based science with teachers: Essential research for lasting reform," Journal of Research in Science Teaching, 38(6): p. 631-645.

41. Tamim, S.R. and M.M. Grant, (2013) "Definitions and uses: Case study of teachers implementing project-based learning," Interdisciplinary Journal of problem-based learning, 7(2): p. 3. 